\title{
Dissociated Loss of Vibration, Joint Position and Discriminatory Tactile Senses in Disease of Spinal Cord and Brain
}

\author{
R.T. Ross
}

\begin{abstract}
The clinical functions of the posterior columns of the spinal cord and the signs of disease of these structures have been debated for years. Todd in 1847 and Schiff in 1858 knew the functions of the posterior columns and 10 years later Brown-Séquard knew as well. Reynolds, Romberg, and Duchenne, each described a posterior column syndrome based on a disease in which the primary lesion was not in the posterior columns. In the last 150 years almost every white matter structure of the cord has been credited with serving the sensations that we now know are a function of the posterior columns. Vibration, joint position and movement as well as discriminatory touch each seem to be served by separate fibres of the posterior columns and medial lemniscus. There is evidence of this in cat and man. These sensations may be lost individually, totally, or in certain stereotyped combinations. Vibration or joint sense is commonly lost alone. When a discriminatory touch sensation is lost with one other sense, it is almost inevitably joint position sense. Absent discriminatory touch and vibration sense with normal joint position sense appears to be unknown. This functional separation continues into the thalamus. At the highest level there is no evidence that vibration sense has any conscious somatosensory cortical affiliation, while joint position and discriminatory touch senses definitely do.
\end{abstract}

\begin{abstract}
RÉSUMÉ: Dissociation de la perception des vibrations, de la position articulaire et de la discrimination tactile dans les maladies de la moelle épinière et du cerveau. Les fonctions cliniques des cordons postérieurs de la moelle épinière et les signes d'atteinte de ces structures ont fait l'objet de discussions depuis des années. Todd, en 1847, et Schiff, en 1858, connaissaient les fonctions des cordons postérieurs et, 10 ans plus tard, Brown-Séquard les connaissait également. Reynolds, Romberg et Duchenne ont tous décrit un syndrome basé sur une maladie dont la lésion primaire n'était pas située au niveau des cordons postérieurs. Au cours des 150 dernières années, presque toutes les structures de la substance blanche de la moelle épinière ont été désignées comme des voies sensitives, fonction que nous reconnaissons maintenant comme appartenant aux cordons postérieurs. La perception des vibrations, de la position et du mouvement des articulations, de même qui la discrimination tactile semblent être servies par des fibres distinctes situées dans les cordons postérieurs et le lemniscus médian. Il en existe des preuves chez le chat et chez l'homme. Ces sensibilités peuvent être abolies individuellement, totalement, ou selon certaines combinaisons stéréotypées. La perception des vibrations ou de la position des articulations est souvent abolie de façon isolée. Quand une des discriminations tactiles est abolie en même temps qu'une autre sensibilité, c'est presqu'invariablement la perception de la position articulaire. L'absence de la discrimination tactile et de la perception des vibrations avec une perception normale de la position articulaire semble inconnue. Cette dichotomie fonctionnelle se retrouve jusque dans le thalamus. Au niveau supérieur, il n'y a pas d'évidence que la perception des vibrations a des affiliations corticales somesthésiques conscientes, alors que la perception de la position articulaire et la discrimination tactile en ont incontestablement.
\end{abstract}

Can. J.Neurol. Sci. 1991; 18: 312-320

The functions of the posterior columns of the spinal cord have been disputed intermittently for over a century. At times there seems to have been general agreement. Then new evidence, often based on fallacious assumptions and inaccurate observations, has intruded on the conventional wisdom and the matter has been in the air again. The common bedside tests of posterior column function are the patient's identification of vibration, joint position and movements, and discriminatory touch of several kinds.
Vibration sense was considered a discrete sensation by Weber in 1842.1 Ten years later Valentin ${ }^{2}$ altered peripheral nerve function with heat, cold, and ischemia, changing vibratory perception. Unfortunately, this observation was largely neglected until relatively recently. $\operatorname{Rumpf}^{3}$ introduced the tuning fork to clinical medicine and following the detailed clinical studies of Symms ${ }^{4}$ in Britain and Williamson ${ }^{5}$ in America, the testing of vibration sense became part of the bedside examination of the neurologically impaired.

From the Section of Neurology, Department of Medicine, University of Manitoba, Winnipeg, Canada

Received September 5, 1990. Accepted in final form February 11, 1991

Reprint requests to: R.T. Ross, MD, Neurology, PE 126 - 820 Sherbrook Street, Winnipeg, Canada R3A IR9 
Joint position and movement sense are the most difficult and deceptive posterior column functions to assess. Carpenter and Sutin $^{6}$ and others have recognized that even in the presence of profound posterior column disease the location of a limb and the direction of its movement may be recognized via touch and pressure imparted by the examiner and conveyed by the spinothalamic complex.

Simple touch is usually normal in disease of the posterior columns or only an occasional touch is missed when subtle testing is used. Discriminatory or complex touch including twopoint discrimination, touch localization, the direction of movement of an object drawn on the skin, stereognosis, and graphesthesia may be grossly disturbed. The last of these is probably the most objective and verifiable bedside test of posterior column disease. There appears to be an association between joint position sense and tactile discriminatory functions. When the former is abnormal there is commonly a defect of two-point discrimination, location of a stationary touch, or the direction of a moving touch, or graphesthesia. Foerster ${ }^{7}$ considered twopoint discrimination a reliable and sensitive test of posterior column function. If damaged posterior columns recover, two-point discrimination remains abnormal the longest. Foerster ${ }^{7}$ also believed that failure of the patient to recognize the direction of a line drawn on the skin (the basis of graphesthesia) could exist as a single sign of posterior column disease. Wartenburg8 introduced graphesthesia to North America in 1939, clearly attributing its origins to Foerster. There seems to be little consensus on the exclusivity or sensitivity of astereognosis. Signs of impairment of the posterior part of the cord commonly change over time. Many have described marked improvement in the months and years after posterior column trauma and surgery. ${ }^{9-13}$

Symptomatically, the patient with posterior column disease may be subject to profound loss of dexterity and manipulative skills as well as ataxia. Almost all the zetetics of posterior column function have observed that among the more common distressing symptoms are increased and unpleasant sensations in response to the stimulation of pain and normal heat, cold, tickle, and sometimes touch in an area served by a diseased posterior column.

In 1847, the genius Irish neurologist Robert Bentley Todd ${ }^{14}$ correctly suggested, "The antero-lateral columns (of the spinal cord) are compounded in function, serving motion and sensation" and the posterior columns were not concerned with "ordinary sensibility". He attributed the gait ataxia of tabes dorsalis to posterior column disease probably without knowledge of the contributions of the abnormal posterior roots and ganglia.

Brown-Séquard 15 was convinced "that the central gray matter was the principal conductor of the sensitive impressions in the spinal cord". He also stated that sensory loss "must depend on the section of the commissural fibres of the spinal cord". Initially, he believed that section of the posterior columns with intact central gray matter caused no change in sensation. Following Todd's 1847 descriptions, the posterior column "syndrome" evolved. Cardinal contributors (mostly from studies on patients with tabes dorsalis) were Romberg in 1851, Reynolds in 1855 , and Duchenne in 1858, who introduced the term progressive locomotor ataxia. ${ }^{16}$ Schiff 17 believed his "main achievement was the discovery of the aesthodic and kinaesthodic modes of sensations". The former, pain and temperature sensations, crossed the midline in the gray matter. The latter ascended in the posterior columns on the same side as they entered the cord.

The neurological complication of pernicious anemia, posterolateral sclerosis of the spinal cord, contributed substantial misinformation on posterior column function. It became a clinical cliché that vibration sense was more abnormal than joint position sense in the cord disease of pernicious anemia and the reverse was found in tabes dorsalis. The components of the clinical picture due to peripheral nerve disease in the former and posterior nerve root and ganglion disease in the latter were recognized relatively late. The elegant study of the myelopathy of pernicious anemia by Pant et al. 18 did little to clarify the relationship between clinical signs and the location of the cord lesions.

The early, disproportionate, and selective loss of vibration sense and ankle reflexes in the apparently healthy aged population and in patients with diabetes mellitus and other peripheral nerve disorders has been well described and exemplified by the work of Gilliatt and Willison ${ }^{19}$ and Lascelles and Thomas. ${ }^{20}$ The contributions of the diseased peripheral nerve and nerve root to the clinical pictures of tabes dorsalis and posterolateral sclerosis have been established. What Valentin ${ }^{2}$ demonstrated experimentally in 1852 is now appreciated by all.

Reports suggesting the posterior column syndrome is of doubtful validity are of two kinds. One describes patients who have lost vibration and/or joint position sense and the lesion in the cord is apparently not in the posterior columns. ${ }^{21.22}$ The second reports devastating lesions of the posterior spinal cord with preservation of these sensations. ${ }^{12}$ Brodal suggested that joint position sense might be carried by the dorsal spinocerebellar tract. 23

The current thinking on cord function has returned to the ideas of Todd ${ }^{14}$ (1847) and Schiff ${ }^{17}$ (1858). Nathan et al. ${ }^{10}$ have drawn on the world's literature plus an enormous personal experience with patients subjected to anterolateral (104 patients in this group alone) or posterior cordotomy and commissurotomy. A summary of their experience indicates conventional views of posterior cord function are correct. When the posterior columns are removed, touch and pressure sensations are intact but touch discrimination is seriously impaired. Although examination of the patient may reveal only minor abnormalities, his ability to cope with the activities of daily living is seriously compromised. Vibration, joint position and movement sensations are lost. These sensory abnormalities were not found with confirmed exclusive or combined lesions of the lateral, anterior, or anterolateral portions of the cord.

There is similar evidence in the paper of Lockard and Kempe. ${ }^{24}$ They were specifically interested in the notion that joint position and movement senses from the legs might be served by the dorsal spinocerebellar tract as suggested by Brodal, 23 Ross et al., ${ }^{22}$ and others. They presented two kinds of contrary evidence. The first was four patients with anatomically proven posterior column lesions and intact dorsal spinocerebellar tracts each of whom had lost position and vibration senses as well as tactile discrimination. The second consisted of 62 patients who had surgical section of the spinal tract of the fifth 
cranial nerve $5 \mathrm{~mm}$ below the obex for the relief of intractable pain. In order to cut the spinal tract, the overlying dorsal spinocerebellar tract was necessarily incised as well. In the majority, the extent of the anatomical lesion was verified at autopsy. None had impaired vibration, joint position, or discriminatory touch sensations.

In 1847 and 1988 the same ideas prevailed about the back of the spinal cord. Between these dates almost every other portion of the spinal cord has been credited with what is now known to be the true functions of the posterior columns.

There is evidence of dissociated loss of some of these sensations at many levels of the nervous system. A progressive dorsal cord lesion may affect vibration sense first and more severely, while the only sign of a somatosensory cortex lesion may be defective joint position and movement senses. The following observations are presented in a caudal-rostral direction.

\section{Spinal Cord}

When the spinal cord is compressed the area of the cord abutting the lesion need not be the most severely damaged. However, there is some consistency in the signs and symptoms accompanying cord compression.

In compression of the thoracic and lumbar spinal cord, if a defect of posterior column function is partial, vibration sense seems most vulnerable and joint position most durable. Weinstein and Bender ${ }^{25}$ followed six patients with spinal cord compression at various levels from the sixth cervical to the eleventh thoracic. All had normal joint position sense and severely defective vibration sense. Three recovered their vibration sense post-operatively. The authors suggested position sense might be served by posterior columns as well as dorsal spinocerebellar tracts. This has been disproven by the work of Lockard and Kempe ${ }^{24}$ and others.

Intrinsic cord lesions are often more revealing. The following three anatomically verified examples have a possible common explanation for the dissociation of vibration and joint position sense. Netsky ${ }^{21}$ reported eight patients with syringomyelia followed for 20 years. His third patient had diminished vibration sense in the upper limbs but it was normal elsewhere. Joint position sense was normal everywhere. He suggested vibration sense was transmitted in the lateral columns. The syringomyelic cavity had replaced the gray matter and extended across the commissure dorsal to the central canal.

The patient of Ross et al. ${ }^{22}$ had an anterior spinal artery occlusion with infarction from the seventh cervical to the third thoracic cord segments. A Brown-Séquard syndrome with right sided loss of vibration and joint position sense and contralateral loss of pain and temperature was present. In the anteroposterior plane the lesion extended dorsally about a third of the distance from the commissure to the dorsal surface of the cord at the seventh cervical segment. It also involved the central gray matter and the ventral aspects of the fasiculus gracilis immediately dorsal to the commissure, greater on the right. These authors also suggested that position and vibration sensations might be carried in the dorsal spinocerebellar tracts. The patient of Nathan et al. ${ }^{10}$ (E.W.) thrombosed her anterior spinal artery, with infarction of the anterior two-thirds of the cord from the ninth thoracic segment caudally. The line of demarcation between infarcted and normal cord passed through the posterior columns slightly posterior to the gray matter, infarcting the most anterior aspects of the columns. Her touch, two-point discrimination, graphesthesia, position, and joint movement were normal in the legs and toes. However, vibration was felt irregularly, diminished, and sometimes not at all.

These findings may be explained without recourse to the suggestion that either the lateral columns or dorsal spinocerebellar tracts serve traditional posterior column functions. There are two pieces of information that are applicable.

The first concerns the functional laminations of the posterior column which suggest that vibration sense is anatomically related to the most anterior aspects of the posterior column close to the commissure, discriminatory touch is most posterior, and joint position sense in between. The evidence is derived from both animal and human studies. Uddenberg ${ }^{26}$ demonstrated this arrangement in the cat. As shown in Figure 1, fibres from hair and claw receptors occupy the superficial part of the column, while fibres from vibrations receptors lie in the deeper parts immediately posterior to the commissure. Fibres from muscle receptors occupy an intermediate position. Schneider et al.27 thought the posterior columns were similarly laminated in man (Figure 2). These conclusions were derived from their surgical experience with central cord syndromes including syringomyelia. This anatomical arrangement in man would account for the abnormality of vibration in these three patients and preservation of all other posterior column sensations in two of the three patients, and loss of vibration and passive movement with preservation of discriminatory touch in the third. In addition, this arrangement explains why a superficial posterior lesion may present with disturbed discriminatory touch and joint position sense but normal vibration sense, while a deep anterior lesion near the central canal may present with the opposite physical signs.

The second piece of evidence is the topographical anatomy of the posterior columns as provided by Smith and Deacon. ${ }^{28}$ From Figure $3 \mathrm{~A}$ the fasiculus cuneatus occupies most of the ventral aspect of the posterior columns abutting the commissure from the second to the sixth cervical cord segments. At C3 it occupies all of the ventral aspect. In Netsky's ${ }^{21}$ patient number 3 , the gray matter syrinx crossing in the commissure dorsal to the central canal could readily involve this ventral "foot" of the fasiculus cuneatus, with resulting vibration sense loss in the upper limbs and preservation of this sensation in the legs. Similarly, Figure 3B is helpful in explaining the findings in the patient of Ross et al. ${ }^{22}$ From the seventh cervical to the second thoracic cord segments, the level of their patient's infarct, the "foot" of the fasiculus gracilis occupies the entire ventral aspect of the posterior column and is part of the infarcted area shown in their figure $2 \mathrm{~F}$. A similar explanation would apply to the patient with thombosis of the anterior spinal artery described by Nathan et al. ${ }^{10}$

\section{Commissurotomy}

An incision in the posteromedian sulcus deep enough to transect the commissure for the relief of intractable pain has provided some information on the anatomy of the posterior columns.

Putnam ${ }^{29}$ completely bisected the commissure from the fourth cervical to the third thoracic cord segments. Even if the 


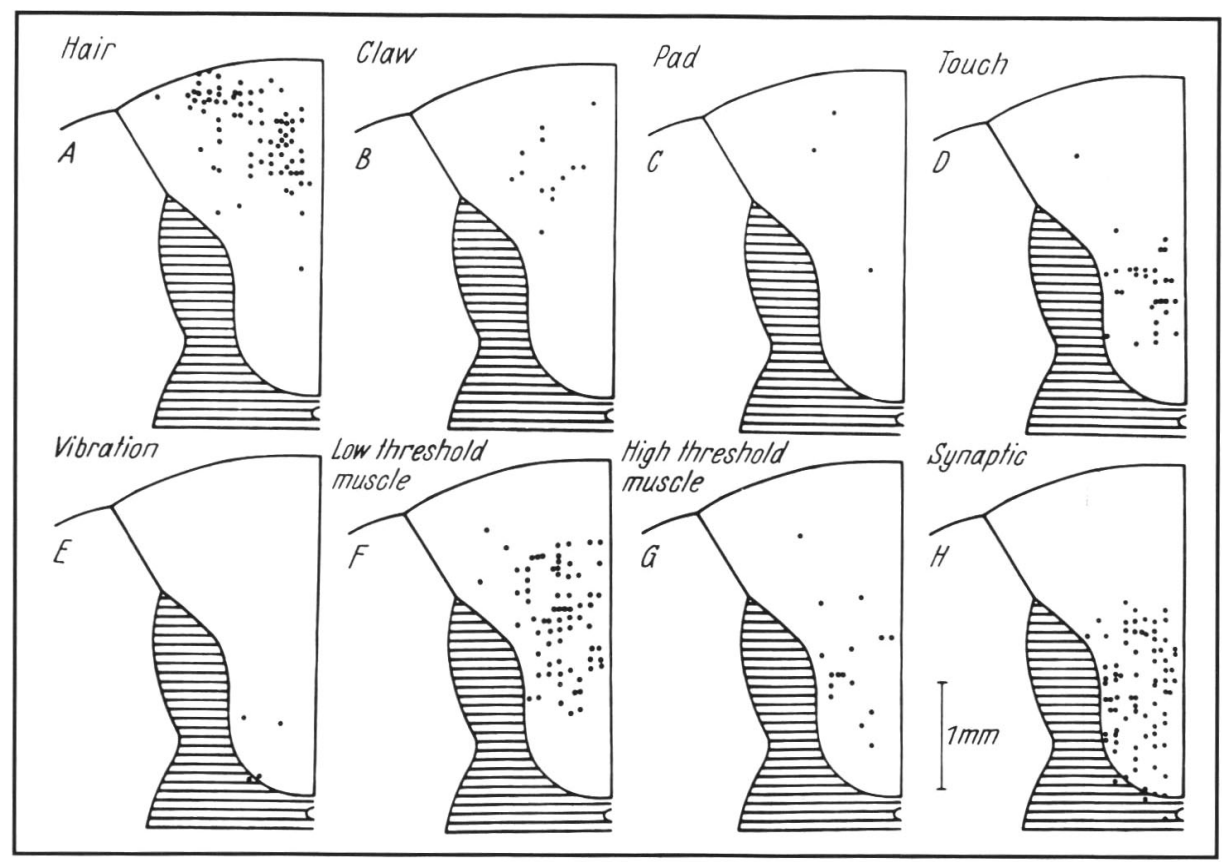

Figure 1 - Differential distribution in cat dorsal funiculus of fibres belonging to different groups. The groups consists of fibres from hair receptors $(A)$, claw receptors $(B)$, pad pressure receptors $(C)$, touch receptors $(D)$, vibration receptors $(E)$, low threshold (less than $1.5 T$ ) muscle afferents $(F)$, high threshold muscle afferents $(G)$, and synaptically activated neurones $(H)$. The diagrams represent left half of dorsal funiculus in third cervical segment. (Reproduced with permission from N. Uddenberg, Brain Research. 1968:4:367-376, Reference 26.)

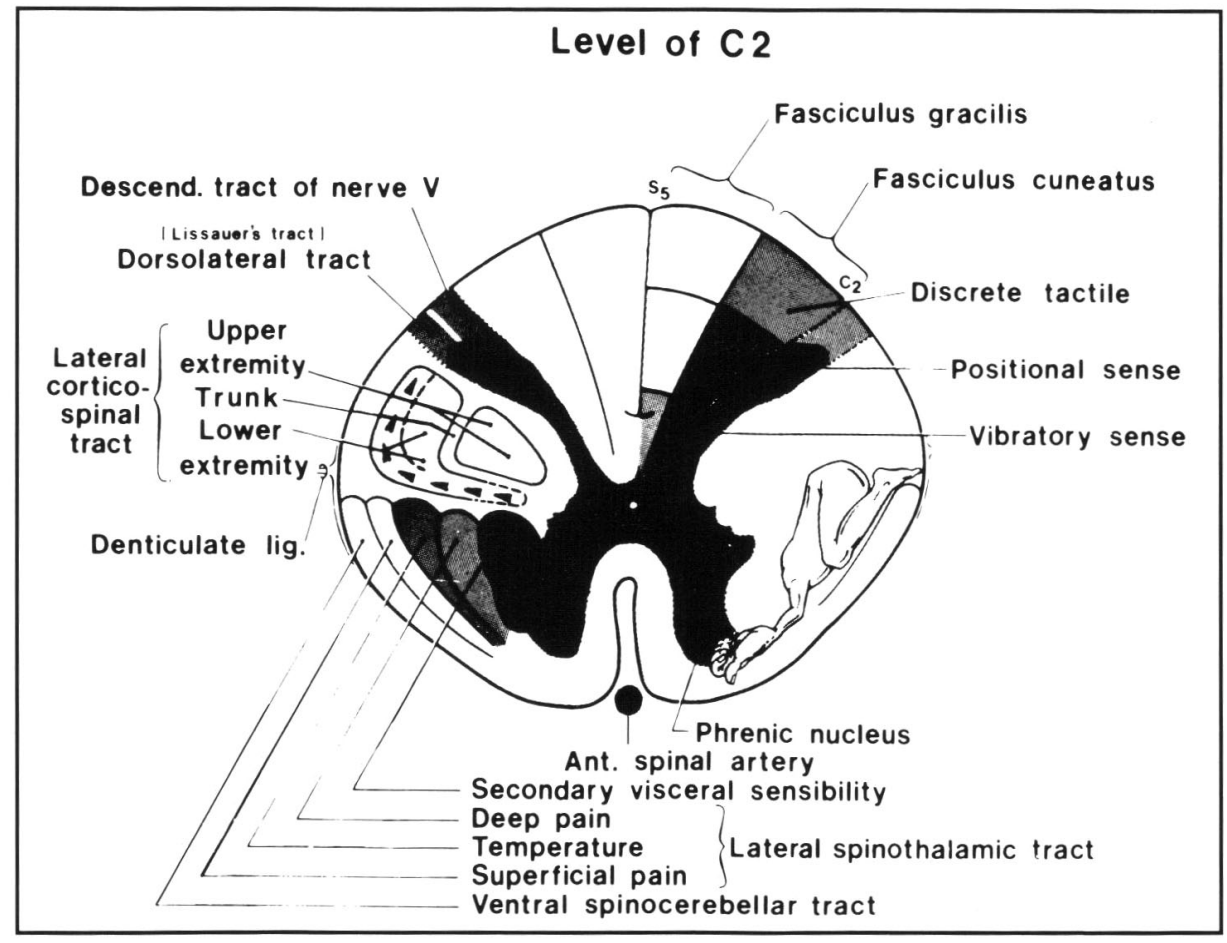

Figure 2 - Suggested functional lamination of the posterior columns in man (Reproduced with permission from Schneider RC. Correlative Neurosurgery, 3rd edition, 1982, p. 1022, courtesy of Charles C. Thomas, Publisher, Reference 27.) 
myelotome was precisely in the midline for the full depth of the incision, the funiculus gracilis is so narrow in its ventral area at some of these cord segments it would have to be damaged (see Figure 3B, segments $\mathrm{C} 3$ and 5). Putnam's patient had only absent vibration sense in the legs as a post-operative complication. There is similar evidence in the commissurotomy studies of Cook and Kawakami ${ }^{30}$ and Cook et al. ${ }^{31}$ If the myelotome is oblique rather than vertical or parallel to rather than in the posteromedial sulcus, the greatest damage will be in the most anterior aspects of the fasiculus gracilis. The most common physical sign after commissurotomy is abnormal vibration sense in the legs. It is often transient.

\section{Cervical Spinal Cord}

Weinstein and Bender ${ }^{25}$ knew that lesions of the cervical cord usually resulted in the opposite clinical signs, namely, major defects in joint position sense with relative preservation of vibration sense. Savettieri et al. ${ }^{32}$ presented similar information. Both of their patients had cord compression at the C3-4

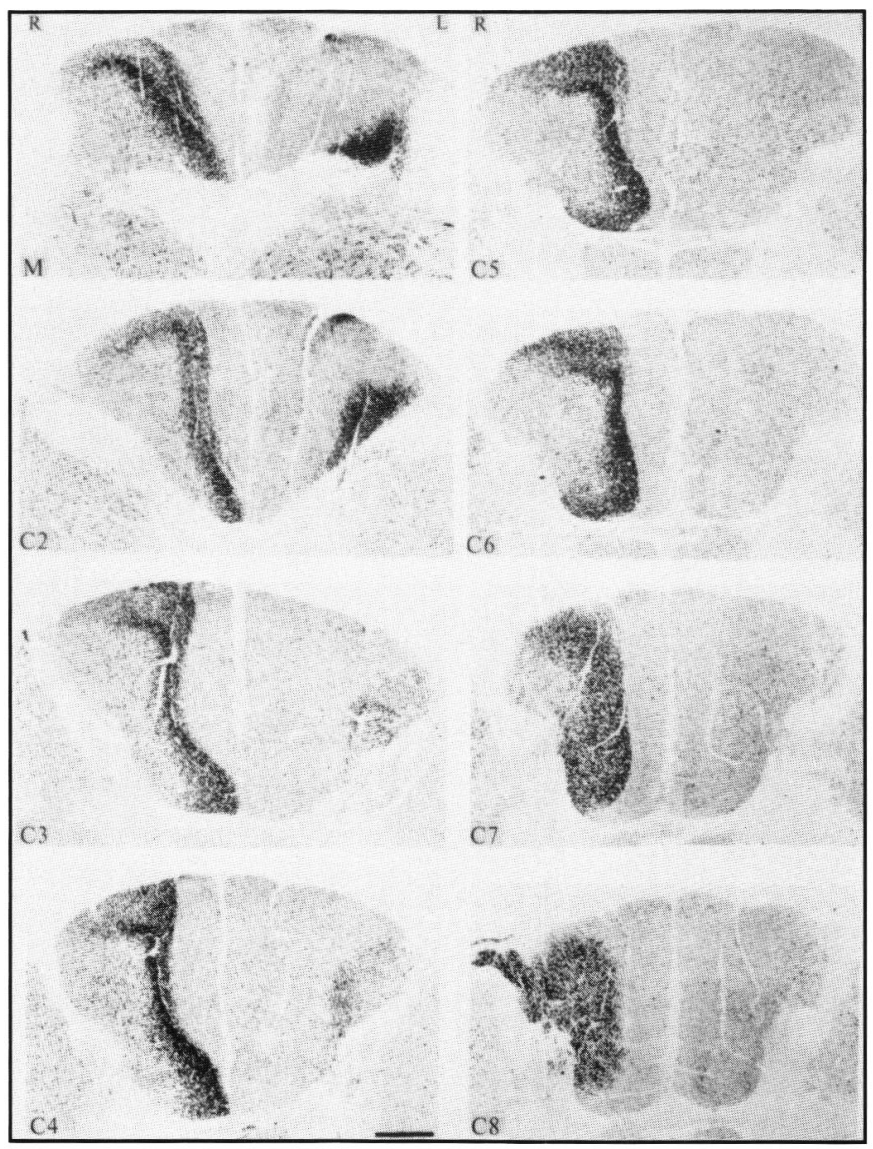

Figure 3 - A) Degeneration of fasiculi cuneati from posterior root lesions of $C 8, T 1$ and $T 2$ on the right and $C 2$ on the left, shown in sections from cervical cord and medulla $(M)$. Black staining indicates degeneration.

Marchi preparation.

$B a r=1 \mathrm{~mm}$. disc space with clinical plus somatosensory evoked response and myelographic evidence of cord compromise. One had slight impairment of vibration sense in the legs and the other major impairment below the costal margin. However, both had pseudo-athetosis in the hands (more marked with the eyes closed) with normal touch, pain, temperature, and vibration senses. Joint position sense, two-point discrimination and tactile localization were seriously impaired in both patients in both hands. The selective physical signs of these patients suggest the maximum lesions were in the most posterior and middle parts of the cuneati.

\section{Foramen Magnum}

Cushing, ${ }^{33}$ Rubenstein, ${ }^{34}$ Symonds and Meadows, ${ }^{35}$ as well as Weinstein and Bender ${ }^{25}$ have all reported on the sensory defects from compressive lesions at the foramen magnum. As in lesions of the cervical cord, vibration sense was little reduced relative to the other senses. The available anatomical studies do not explain these selective sensory deficits.

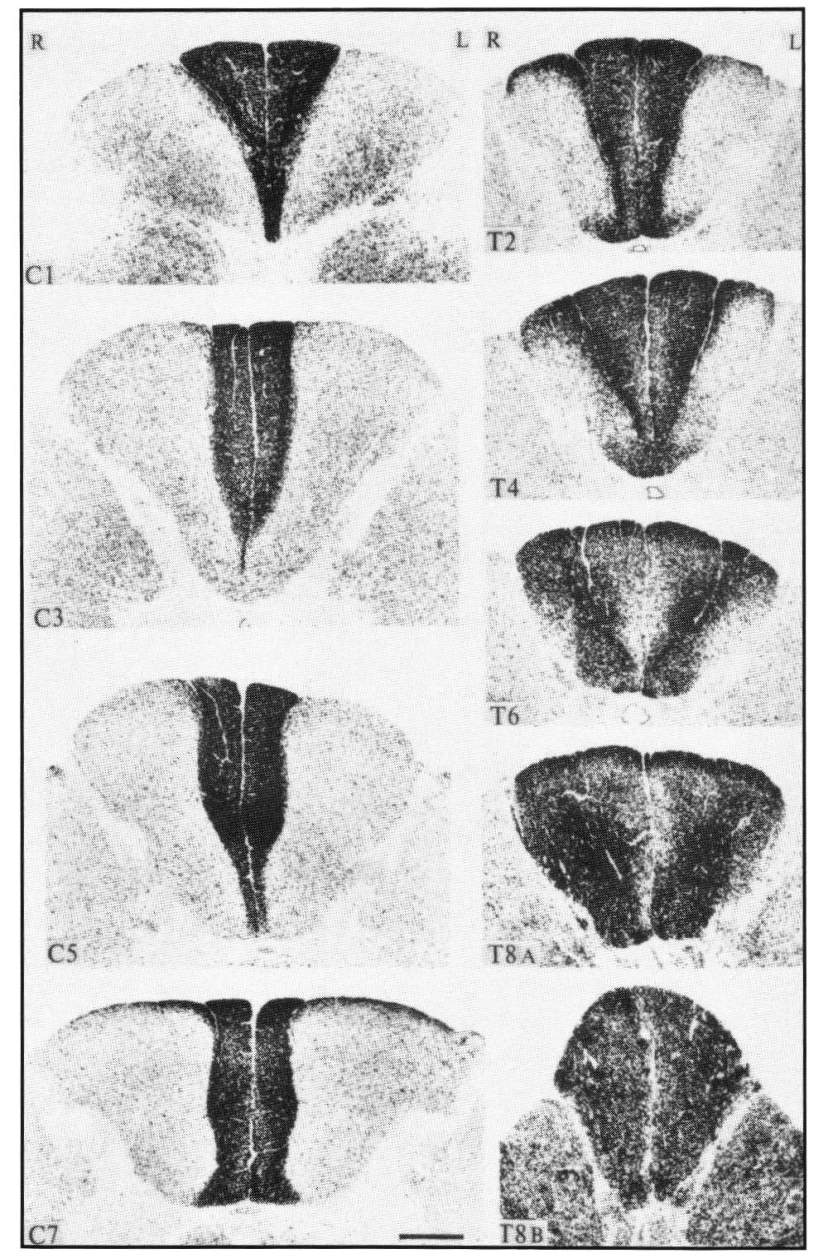

Figure $3-B$ ) Degeneration of both fasiculi gracilis following transverse lesions of $T 7$ and 8. Black staining indicates degeneration Marchi preparation.

Bar $=1 \mathrm{~mm}$.

(Reproduced with permission from Smith $M C$ and Deacon $P$, Brain 1984; 107: 671.698, Reference 28.) 


\section{Medial Lemniscus}

There is evidence that lesions of the medial lemniscus (ML) may impair one or several but not necessarily all of these sensations. In addition to a possible functional lamination, however, there is a definite somatotopic lamination. Brodal23a illustrates the ML in the medulla as a headless man with posterior column senses from the arms and upper body in the dorsal portion while these senses from the lower body and legs are in the ventral parts. How the fibre arrangement in the ML accommodates both a specific sensory and somatotopic pattern is not known. Head and Holmes ${ }^{36}$ reported a patient with what they considered "typical" occlusion of the left posterior inferior cerebellar artery (case \#3). He was examined seven months after the event and the signs included diminished appreciation of pressure and joint position and movement in the right arm and leg. Vibration sense was normal everywhere as were all tactile discriminatory sensations. Although there was no anatomical verification of the lesion, the details conform to what is commonly seen in lateral medullary infarction. Possibly the infarct extended far enough medially to encompass only a portion of the medial lemniscus with preservation of vibration and discriminatory touch and loss of joint position sense. The following case report of pontine hemorrhage reveals selective sparing of vibration sense.

\section{Case Report}

MN, a 38 year old female, collapsed without loss of consciousness. When examined four hours later she was complaining of vertigo and loss of control of her left arm and leg. These limbs were moving in a constant, restless, choreic, way. Ocular movement testing revealed Fisher's ${ }^{37}$ "one and one half syndrome". Up and down gaze and convergence were normal. The right pupil was smaller than the left, both reacted to light and near. The entire right face was paretic and did not perspire. All sensations were normal on the right face and head. Both corneal reflexes were absent. All sensations, coordination, and strength were normal in the right arm and leg. There was loss of touch, pressure, pain, and temperature appreciation over the entire left half body except for the upper and lower lips, nasal orifice, and lower part of the nasal ala where pain and temperature were perceived normally. The left half tongue was anesthetic. She did not know where her left arm and leg were if she did not look at them and could not tell when they were moved or the direction of the movement at any joint. Vibration was "fuzzy" but present on the left. She had bilateral extensor plantar responses and all tendon reflexes were pathologically increased. Her general investigations including vertebral and renal angiography, ultrasound examination of her adrenals, echocardiography, and urinary vanillylmandelic acid, metanephrines and catecholamines, were normal. The only changes found three, five, and six months after the ictus were cessation of the left sided involuntary movements and the right extensor plantar responses had become flexor. She could not stand or walk. The magnetic resonance images of her brain are shown in Figure $4 a$ and $b$, 12 months after the acute event. The cavity, although over the midline, produced permanent signs respecting the right half dorsal pons only. In addition to the facial and ocular pareses, all spinothalamic tract fibres and all secondary trigeminal fibres on the right were interrupted. All medial lemniscus fibres except those serving vibration sense were interrupted and there was transient slight impairment in this sense on the left half body, greater in the upper than the lower limb.

Graveleau et al. ${ }^{38}$ have reported a somewhat similar situation from a left pontine hemorrhage (Figure 5a and b). Their patient retained all superficial sensations except for occasional errors of pain perception from the right foot and leg. Vibration was present but less than normal, while the major defects were loss of joint position sense plus tactile discrimination. The joint position sense loss was more obvious in the upper than lower limb. The lesion in their patient was more medial and anterior than in the case reported above.

\section{Thalamus}

The thalamic nuclei are also divided somatotopically and functionally.

Holmes and Head ${ }^{39}$ reported a patient with Roussy's syndrome due to an anatomically confirmed ventrolateral thalamic infarct. The findings were unilateral spontaneous pain, elevated pain threshold with absent touch, joint position sense, and temperature appreciation on the same side. Vibration was normal. Patient \#4 of Head and Holmes ${ }^{36}$ had an anatomically confirmed tumor of the right corpora quadrigemina, crus and anterior pons. The signs included pseudo-athetosis and ataxia, loss of joint position sense, discriminatory touch, stereognosis and pain perception in the left arm and leg. Vibration was normal. The reverse type of selective loss has been described by Fisher. ${ }^{40} \mathrm{His}$ patient had decreased pain, touch, and vibration senses in the face, tongue, arm, and hand, with less involvement of the foot.
A

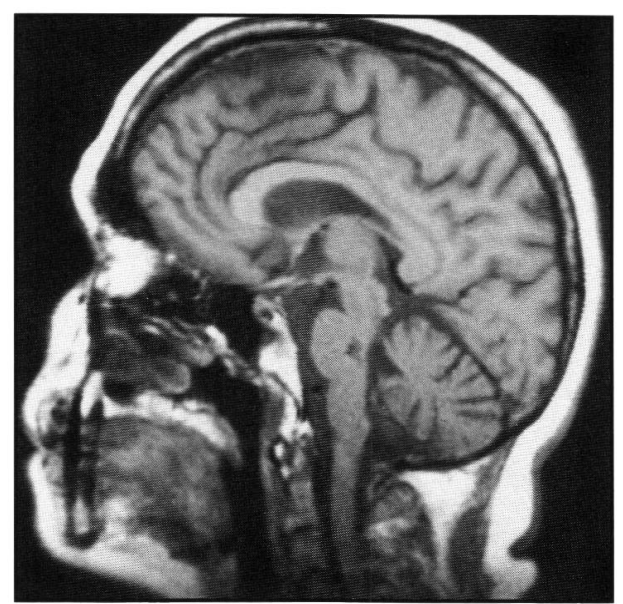

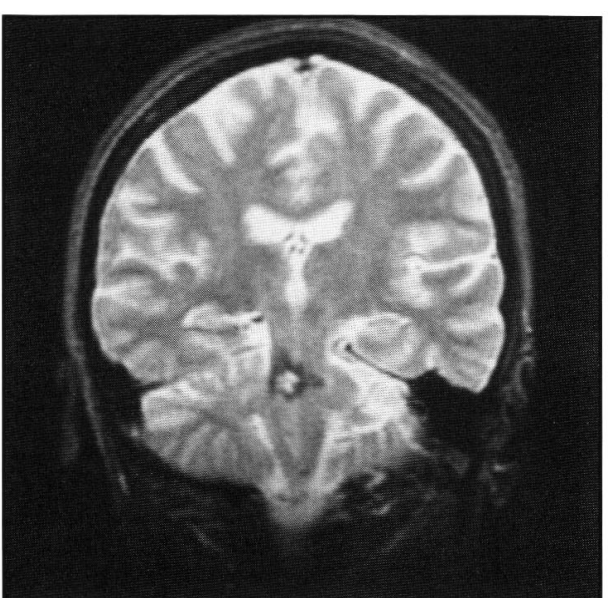

Figure 4 - Sagittal and coronal magnetic resonance image views of brain and brainstem of patient MN 12 months after ictus. Cavity is predominantly right sided but crosses the midline.

(A, proton density and $\boldsymbol{B}, T 2$ weighted images.)

(Reproduced courtesy of the Mayo Clinic.) 
Joint position sense, discriminatory touch and graphesthesia, were normal. The lesion was a $6 \mathrm{~mm} \times 3 \mathrm{~mm}$ cavity in the posteroventral thalamus. The patient described by Sacco et al. ${ }^{41}$ had normal touch, pain, cold, and vibration senses on the left, but abnormal joint position sense, stereognosis, and graphesthesia on the same side. Nuclear magnetic resonance imaging revealed a ventral posterolateral nucleus infarct in the right thalamus. Fibres of the ML terminate almost entirely in the caudal portion of the ventral posterolateral nucleus of the thalamus. Further, fibres originating in the nucleus cuneatus terminate medially while those from the gracilis end laterally. $6 \mathrm{a}$

Although this somatotopic relationship is generally accepted, a functional division of thalamic structure to account for joint position sense loss and preserved vibration 41,36 or the reverse $\mathrm{u}^{40}$ is unexplained anatomically.

\section{Cortex}

In 1981 Brodal23b discussed symptoms related to lesions of the somatosensory cortex (Brodmann's areas 3, 1, 2)..."vibratory and joint position sense are permanently reduced or practically abolished". There is considerable evidence that this is incorrect. Marie and Bouttier ${ }^{42}$ knew that the usual dissociated sensory findings from lesions at the cortical level were loss of joint position sense with preservation of vibration. Holmes 43 stated "the tuning fork is one of the least useful tests in cortical disease, for as Head has shown the appreciation of vibration is possible through the thalamus alone, and there is usually at the most only a subjective difference between parts where a disturbance of cortical sensibility exists and the corresponding normal parts". Dandy 44 reported two patients who had hemispherectomies. The patient with a relatively superficial tumor had defective joint position and movement senses in the contralateral limbs while vibration was less acute but present. In the second patient with the deeper tumor, presumably into the thalamus, vibration and all other sensations were lost. Of the 21 patients with cerebral tumors, largely parietal, reported by Weinstein and Bender ${ }^{25}$ seven had absent position with normal or near normal vibration sense. When both were abnormal, position sense loss was always greater. When position sense was absent it was usually accompanied by astereognosis and abnormal two-point discrimination. Derousne et al. ${ }^{45}$ described a patient with a cortical and subcortical infarct demonstrated by computerized tomographic scan to be in the middle of the postcentral gyrus. The thalamus was normal. Touch, pain, hot, cold, and vibration senses were normal. Joint position, stereognosis, graphesthesia, and two-point discrimination senses were severely impaired.

In the cases with autopsy or radiographic verification of lesion sites, there appear to be no examples of cortical or immediate subcortical lesions disrupting vibration sense. Apparently the structures necessary for the perception of vibration do not extend beyond the thalamus.

In summary, there are fragments of evidence that vibration, joint position and discriminatory touch sensations are served by separate anatomical structures in the spinal cord, medial lemniscus, thalamus, and cerebral cortex. In the lumbar and thoracic cords vibratory sense seems most vulnerable from compressive lesions while these lesions in the cervical cord often have their greatest impact on joint position sense. There is evidence from animal (cat) and human studies that the posterior columns have an anteropostero functional lamination. Fibres serving vibration appear to be in the anterior aspects of the posterior column close to the commissure, fibres serving discriminatory touch seem to be most posterior and those related to joint position sense are in between. The somatotopic fibre arrangement of the posterior columns has been greatly clarified by a landmark paper of Smith and Deacon. ${ }^{28}$ In the medial lemniscus in the medulla, upper body sensations are conveyed in the posterior aspects of the lemniscus while those from the lower body are anterior. How fibres are additionally arranged at this level to explain partial
$\mathbf{A}$

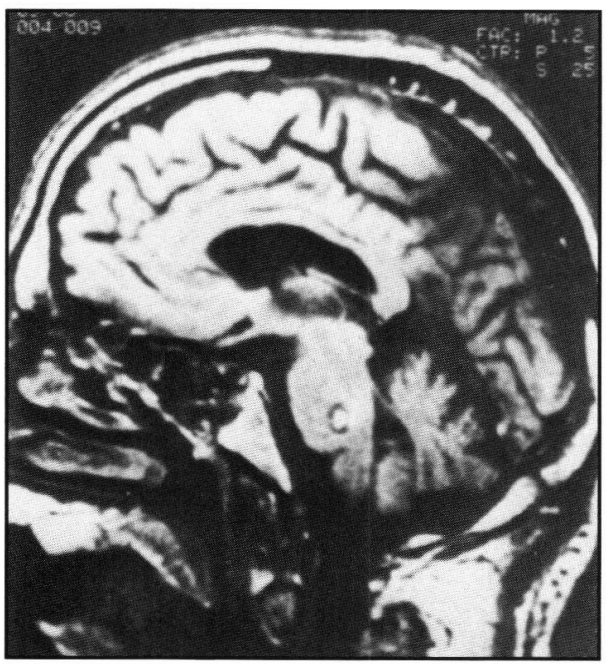

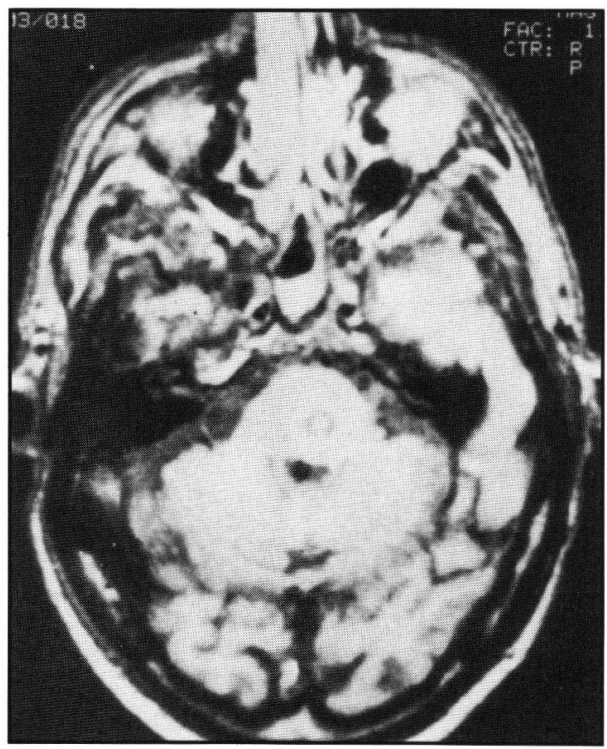

Figure 5 - Sagittal and transverse magnetic resonance image views of patient of Graveleau et al., showing similar cavity as in $4 A \& B .(A \& B, T I$ weighted images.) (reproduced with permission from Graveleau et al., Revue Neurologique 1986; 142: 788-790, Reference 38.) 
sensory defects is not known. The patient of Head and Holmes ${ }^{36}$ after a lateral medullary infarct lost joint position and movement sense while vibration and tactile discrimination were preserved. The same separation may occur in pontine lesions. In the case reported above (MN) all sensations except vibration on half the body were lost due to a pontine hemorrhage. The patient of Graveleau et al. ${ }^{38}$ also with a pontine hematoma lost joint position sense and tactile discrimination while vibration sense was normal.

Vibration sense above the nuclei gracilis and cuneatus seems to be a durable sensory modality raising the possibility of a duplicate or alternate pathway apart from the medial lemniscus.

There is good evidence that separate anatomical areas of the thalamus are related to vibration and joint position sense and there are carefully studied cases of the loss of one of these sensations with preservation of the other. There is no evidence that any structure above the thalamus has any function in the perception of vibration. Many more cases of dissociated proprioceptive sensory loss and the extent and location of the lesion in diseases of the cord, medulla, pons, and thalamus need to be studied. This is a unique system in which the arrangement of the fibres is related to areas of the body as well as the various types of sensation.

\section{ACKNOWLEDGEMENT}

The author wishes to express his gratitude to Dr. Malcolm B. Carpenter, Professor of Anatomy of the Uniformed Services University of the Health Sciences, and Dr. Donald W. Baxter, Director of the Montreal Neurological Institute and Hospital, for their helpful discussions of the fibre arrangement of the medial lemniscus.

Thanks are also extended to Dr. Ph Graveleau and the publishers of Revue Neurologique, Masson SA, for permission to reproduce the CT scans of Figure $5 \mathrm{a}$ and $\mathrm{b}$.

\section{REFERENCES}

1. Weber EH. Tastsinn und Gemeingefühl, in Wagner R: Handwsörterbuch der Physiologie, Leipsig, Brunswick F. Vieweg u Sohn, Vol, 1842: 40I; reprinted in Ostwald W: Klassiker der exacten Wissenschaften, W. Englemann, 1905, No. 5.

2. Valentin G. Ueber die Dauer der Tasteindrüche. Archive für physiologische, Heilkunde 1852; 11: 438-587.

3. Rumpf J. Ueber einen Fall von Syringomyelie nebst Beitragen zur Untersuchung der Sensibilitat. Neurologisches Centralblatt 1889; 8: 185 .

4. Symms JLM. A method of estimating the vibratory sensation, with some notes on its application in diseases of the peripheral and central nervous system. Lancet 1918; i: 217.

5. Williamson RT. Vibration sensation in disease of the central nervous system. Am J Med Sci 1922; 164: 715-727.

6. Carpenter MB, Sutin J. Human Neuroanatomy, 8th edition, Baltimore and London: Williams \& Wilkins, 1983: 269.

6a.Carpenter MB, Sutin J. Human Neuroanatomy, 8th edition, Baltimore and London: Williams \& Wilkins, 1983: 520.

7. Foerster O. Symptomatologie der Erkrankungen des Rückenmarks und seiner Wurzein. Handbuch der Neurologie, Vol 5, Eds. O. Bumke and O. Foerster, Berlin, Springer, 1936: 1.403.

8. Wartenberg R. A 'numeral test' in transverse lesions of the spinal cord. Am J Med Sci 1939; 198: 393-396.

9. Kroll FW. Schwellenuntersuchungen bei Läsionen der afferenten Leitungsbahnen. Zeitschrift für die Gesamte Neurologie und Psychiatrie 1930; 128: 751-776.

10. Nathan PW, Smith MC, Cook AW. Sensory effects in man of lesions of the posterior columns and of some other afferent pathways. Brain 1986; 109: 1003-1041.
11. Rabiner AM, Browder J. Concerning the conduction of touch and deep sensibilities through the spinal cord. Trans Am Neurol Assoc 1948; 73: 137-142.

12. Cook AW, Browder EJ. Functions of posterior columns in man. Arch Neurol 1965; 12: 72-79.

13. Wall PD. The sensory and motor role of impulses traveling in the dorsal columns towards cerebral cortex. Brain 1970; 93: 505524.

14. Todd RB. Physiology of nervous system in: The Cyclopedia of Anatomy and Physiology 1835-1858, Vol 2, London: Longman, Brown, Green, Longmans \& Roberts, 1847: 585-723.

15. Brown-Séquard. Course of Lectures on the Physiology and Pathology of the Central Nervous System. Philadelphia: Collins, 1860.

16. Spillane JD. The Doctrine of the Nerves, Chapters in the History of Neurology. Oxford: Oxford University Press, 1981: 320.

17. Schiff M. Lehrbuch der Physiology der Menschen. Lahr, Verlag, Von M. Schauenberg (1858-59), Vol 1, 1858: 235.

18. Pant SS, Ashbury AK, Richardson EP. The myelopathy of pernicious anemia. Acta Neurol Scan (Supplement) 1968; 44: 136.

19. Gilliatt RW, Willison RG. Peripheral nerve conduction in diabetic neuropathy. J Neurol Neurosurgy Psychiatry 1962; 25: 11-18.

20. Lascelles RG, Thomas PK. Changes due to age in internodal length in the sural nerve in man. J Neurol Neurosurgy Psychiatry 1966; 29: $40-44$

21. Netsky MG. Syringomyelia - a clinicopathologic study. Arch Neurol Psych 1953; 70: 741-777.

22. Ross ED, Kirkpatrick JB, Lastimosa ACB. Position and vibration sensations: function of the dorsal spinocerebellar tracts. Ann Neurol 1979; 5: 171-176.

23. Brodal A. Neurological Anatomy in Relation to Clinical Medicine, 3rd edition. Oxford and New York: Oxford University Press, 1981: 74-94.

23a. Brodal A. Neurological Anatomy in Relation to Clinical Medicine, 3rd edition. Oxford and New York: Oxford University Press, 1981: 83.

23b.Brodal A. Neurological Anatomy in Relation to Clinical Medicine, 3rd edition. Oxford and New York: Oxford University Press, 1981: 145 .

24. Lockard BI, Kempe LG. Position sense in the lateral funiculus. Neurol Res 1988; 10: 81-85.

25. Weinstein EA, Bender MB. Dissociation of deep sensibility at different levels of the central nervous system. Arch Neurol Psych 1940; 43: 488-497.

26. Uddenberg N. Differential localization in dorsal funiculus of fibres originating from different receptors. Exp Brain Res 1968; 4 367-376.

27. Schneider RC. Correlative Neurosurgery, 3rd edition. Schneider RC, Khan, EA, Crosby EC, Taren JA, Springfield: Charles C. Thomas, 1982: 1022.

28. Smith MC, Deacon P. Topographical anatomy of the posterior columns of the spinal cord in man. Brain 1984; 107:671-698.

29. Putnam TJ. Myelotomy of the commissure. Arch Neurol Psych 1934; 32: 1189-1191.

30. Cook AW, Kawakami Y. Commissural myelotomy. J Neurosurg 1977; 47: 1-6.

31. Cook AW, Nathan PW, Smith MC. Sensory consequences of commissural myelotomy. Brain 1984; 107: 547-568.

32. Savettieri G, Castiglione MG, D'Arpa A, Aiello S, Fierro B. Loss of joint position sense with sparing of vibration sense in two cases of compressive cervical myelopathy. Acta Neurol (Napoli) $1984 ; 6(1): 11-15$

33. Cushing $\boldsymbol{H}$. Notes on a series of intracranial tumours and conditions simulating them. Arch Neurol Psych 1923; 10: 605-668.

34. Rubenstein J. Astereognosis associated with tumours in the region of the foramen magnum. Arch Neurol Psych 1938; 39: 10161032 .

35. Symonds CP, Meadows SP. Compression of the spinal cord in the neighbourhood of the foramen magnum. Brain 1937; 60: 52-84.

36. Head H, Holmes G. Sensory disturbances from cerebral lesions. Brain 1911; 34: 102-254. 
37. Fisher CM. Some neuro-ophthalmological observations. J Neurol Neurosurg Psych 1967; 30: 383-389.

38. Graveleau Ph, Decroix JP, Samson Y, Masson M, Cambier J. Deficit-sensitif isole d'un hemicorps par hematome du pont. Rev Neurol 1986; 142: 788-790.

39. Holmes G, Head H. A case of lesion of the optic thalamus with autopsy. Brain 1911; 34: 255-271.

40. Fisher CM. Thalamic pure sensory stroke - a pathological study. Neurology 1978; 28: 1141-1144.

41. Sacco RL, Bello JA, Traub R, Brust JCM. Selective proprioceptive loss from a thalamic lacunar stroke. Stroke 1987; 18: 1160-1163.
42. Marie P, Bouttier H. Etude cliniques sur les modalities des dissociations de la sensibilities dan les lesions encephaliques. Rev Neurol (Paris) 1922; 1: 1-22.

43. Holmes G. Disorders of sensation produced by cortical lesions. Brain 1927; 50: 413-427.

44. Dandy WE. Physiological studies following extirpation of right cerebral hemisphere in man. Bull John Hopkins Hosp 1933; 53 : 31-51.

45. Derousne C, Mas JL, Bolgert F, Castaigne P. Pure sensory stroke caused by a small cortical infarct in the middle cerebral artery territory. Stroke 1984; 15: 660-662. 